\title{
THE PHENOMENOLOGICAL ANALYSIS OF THE NATURE OF THE FRICTION, FROM THEORETICAL AND EXPERIMENTAL POINT OF VIEW OF AL-AL203-GRAPHITE COMPOSITE /CAST IRON „PIN ON DISC" SLIDING SYSTEM
}

\author{
Ivona Camelia Petre ${ }^{1}$, Ileana Nicoleta Popescu*2 \\ 1,2 Valahia University of Targoviste \\ Sinaia Street No.13, 130004, Targoviste, Romania \\ E-mail: * pinicoleta24@yahoo.com (author correspondent)
}

\begin{abstract}
The theoretical and experimental researches on developing of friction coupling materials that are part of the disc-pad braking systems of vehicle and analysis the tribological behavior of them, has been in the spotlight of the specialists in this field in the past decades. Explaining the phenomena that occur at the level of friction surfaces in relative motion have become increasingly complex and often contradictory. Consequently, in this paper was studied the dry sliding wear behavior and friction coefficient evolution of Al-Al203-Graphite composite /cast iron system. The proposed theoretical model analyze how the friction coefficient is influenced by different factors as: (a) the adhesion coefficient, (b) the deformation of the material during friction and (c) the inclination angle of the microasperity resulting from the friction process for metal-metal or metal-ceramic coupling in general and aluminum based composite / cast iron couple in particular. For the experimental part we used AlZn6MgCu as aluminium matrix (in cast and age hardening state) reinforced with different proportion of graphite and/ or Al2O3 ceramic particles. The composite samples are tribological tested on cast iron disc (300HB hardness) at room temperature using a "pin on disc" machine, at contact pressure of 3.5 and $7.5 \times 10^{-1} \mathrm{MPa}$ and sleeding speed of $3.8 \mathrm{~m} / \mathrm{s}$ under dry sliding conditions.
\end{abstract}

Keywords: Slip motion, Friction coefficient, Composite /Cast iron dry sliding system, Deformation, The shear theoretical model.

\section{Introduction}

Brake pad/disc systems in automobiles must have good wear resistant, stable coefficient of friction during service life, high thermal conductivity, and low thermal expansion properties. Brake pads (also known as friction pad) help in transferring kinetic energy into heat during the application of brake to stop or slow down a moving automobile. The counterparts (brake disc or rotor ) realized the necessary fretting transmission of torsion or brake moment [1,2,3] Mechanical braking system, based on tribological principles, is the oldest and the only one able to stop vehicles within an area of deceleration and braking space required. Due to beneficial characteristics, discontinuous particle reinforced metal matrix composites (MMCs) are particularly attractive because has high thermal conductivity $(60 \%$ of the copper) low specific density, enviromental resistent, correlated with improved wear characteristics data by adding of hard ceramic reinforcement components (Al203, $\mathrm{TiC}, \mathrm{SiC}, \mathrm{ZrO} 2$, etc.) and /or soft (graphite, mica, MoS2, etc.), recommend them that new solutions materials for the brake system [2,3]. On the basis of the weight reductions, inertial forces are also reduced, so as summary weight of vehicles and fuel consumptions are implicitly reduced. Gray cast iron has a good thermal conductivity (necessary for the proper discharge of heat due to friction), good mechanical properties, good wear resistance, and is commonly used as counterparts of Aluminium Matrix Composites (AMC) „pin-on-disc” sliding sistem. Automobile brake system consists of metallic brake disc and brake pads in order to maintain a steady friction coefficient. The coefficient of friction of a material is dependent upon the counterface of material, the surface preparation and operating conditions. 
The coefficient of friction of metals and alloys is affected, in addition to surface cleanliness, by sliding velocity, contact pressure, temperature, gaseous environment, and relative humidity. Thus, in general, the coefficient of friction of metallic pairs increases with an increase in load at low loads because of the oxide film breakdown and/or elastic deformation; it remains at a high value for a load range and begins to drop at high loads because of interfacial changes caused by wear $[4,5]$. The friction coefficient between two surfaces, according to friction theories, is an intrinsic constant of material, but this is confirmed only for a particular speed line, contact pressure, lubrication state, etc. $[6,7,8]$. The analysis of the tribological behavior of these coupling materials (composite/iron cast materials) follows the evolution of friction coefficient, depending on different loading parameters (pressure, sleeding speed).

This paper proposes a theoretical model for characterization of the friction coefficient and comparison of the obtained (calculated) results with the experimental one.

\section{Theoretical model for calculating the coefficient of friction and its application for analyzed materials}

The evolution of the concepts on the nature of friction indicated that friction is based on two fundamental processes, namely the interaction of asperities (adhesion, deformation, breaking) and dissipation of energy. From a phenomenological point of view it is appreciated that the expression of the coefficient of friction comprises three components: adhesion, deformation and furrow. The theoretical model aims to analyze when and how these three components influence the coefficient of friction.

The friction coefficient adhesion component is based on the adhesion theory that friction is due to the destruction of micro-grips between the asperities of the moving surfaces of the slip $[9,10,11]$.

Proximity of the asperities results in an adhesive joint caused by interatomic attractions. The adhesion is considered to be either physical (the hydrogen bonds and van der Waals bonds) or chemical in nature (covalent bonds, ionic or electrostatic bonds, and metallic bonds). The van der Waals forces are always present when two asperities are in close proximity $[3,12]$, and therefore, the cause of these attachments is the existence of the Van der Waals bonds. The coefficient of adhesional friction for a dry contact is

$$
\mu=\frac{\tau}{p_{r}}
$$

where $\tau$ is the shear strength and $p_{r}$ is the mean real pressure.

In the contact area, these micro-wells are formed and permanently destroyed so, we can be spoken of the "third party". Connections created at the level of asperities are sources of energy dissipation. For most solids shear strength of the third body is equal to

$$
\tau=\tau_{o}+\beta \cdot p_{r}
$$

where $\tau_{0}$ is the intrinsic characteristic shear strength of the third body layer, experimentally determinable, for the non-lubricated metal-metal surface: $\tau_{o}=2 \ldots 3 M P a$ and lubricated contact $\tau_{o}=1 . .12,5 \mathrm{MPa}: \quad$ and $\beta \quad$ is a coefficient characteristic of the third body, experimentally determined for dry regime being: $\beta=0,02 \ldots 0,15$, $p_{r}$ is real pressure.

The parameters $\tau_{o}$ and $\beta$ depend on both the surface material and the friction layer in the friction area $[15,16,17]$. Once known these parameters, the mean real pressure $\left(p_{r}\right)$, can be determined analiticaly and also the molecular adhesion coefficient:

$$
f=\frac{F_{t}}{F_{n}}=\frac{\tau \cdot A_{r}}{p_{r} \cdot A_{r}}=\frac{\tau_{o}}{p_{r}}+\beta
$$

where $F_{t}$ is tangential force required for molecular adhesion; $F_{n}$ is the normal force on the contact surface. Knowing the parameters $\tau_{o}$ and $\beta$, for a certain quality of the friction surface and certain operating conditions for which the value of the actual contact pressure $\left(p_{r}\right)$ can be determined, it is possible to determine the molecular adhesion coefficient. It has been experimentally [9] found that this coefficient may vary in the range of $0<f \leq 1$; so for surfaces between which there is no lubricant $f=1$, and for lubricated surfaces we consider $f \cong 0$. This lubrication state for conditions where on lubricating surfaces cannot be introduced (the case under consideration) is similar to the amount of graphite or any other element introduced into the structure of the materials. Thus, it can be appreciated that the composite material AlZn6MgCu+ 5\% Al203 particles (without graphite) have the molecular adhesion coefficient $f=1$, and the AlZn6MgCu with $3 \%$ graphite type materials , we consider that the lubricating state are evaluated by the molecular adhesion coefficient of $f=0$. 
During the sliding of two surfaces, the toughest surface roughness can deform the softer material as a waveform or the micro-shield (furrow). The deformation or micro-sculpting mode depends on how the surfaces are processed and the nature of their materials.

The shear model [13] assumes that the asperities of both surfaces plastically deform, which is likely not the case when a hardened material in contact with a softer one is used. For these conditions, the friction models of Challen et al. [14] can most likely be applied. These models,namely, the wave, the wave removal, and the chip formation models are all based on the plane strain slip-line field theory. In the wave model, the frictional force opposing the sliding of a hard asperity over a soft asperity is assumed to result from the pushing of plastically deformed waves ahead of the hard asperity. For such a model, the frictional force can be calculated without including the fracture of asperities. Therby, the friction coefficient evaluation at sliding of an asperity considered rigid, when on the contact surface there is friction, $[9,11,16,17,18,19]$ is:

$$
\mu_{a}=\frac{A \cdot \sin \alpha+\cos (\arccos f-\alpha)}{A \cdot \cos \alpha+\sin (\arccos f-\alpha)}
$$

where: $f$ is the interfacial strength ratio (coefficient of adhesion) and which is defined to be the ratio of the shear strength of the interfacial film and $\tau$ the shear yield stress of the softer workpiece material; $\alpha$ is the asperity angle (as in Fig.1) and:

$$
A=1+\frac{\pi}{2}+\arccos (f)-2 \alpha-2 \arcsin \frac{\sin (\alpha)}{\sqrt{1-f}}
$$

\section{Experimental Part}

\section{- Selection of materials}

The performance of materials for automotive braking systems consist of hybrid composites with the role of increasing material resistance to gripping and for wear reduction of disc (rotor) brake. It has been chosen to use the AlZn6MgCu alloy for the matrix, a high strength aluminium alloy with good resistance to stress-corrosion cracking used in transport industry and military equipment [20].

The strength and hardness of chosen $\mathrm{Al}-\mathrm{Zn}$ matrix are enhanced by the formation of extremely small uniformly dispersed second-phase particles within the original phase matrix in a process known as precipitation or age hardening [21,22]. The precipitate particles act as obstacles to dislocation movement and thereby strengthen by age hardening processes the heat-treated Al-Zn alloys. The aging kinetics is generally accelerated of addition of hard ceramic reinforcing elements (as $\mathrm{SiC}, \mathrm{Al}_{2} \mathrm{O}_{3}$, etc.) in matrix alloys, thus leading to improving hardness of materials. For this reason (to increase the mechanical resistance) and also in addition, for increasing wear resistance in composites, we chosen as reinforcement $\mathrm{Al}_{2} \mathrm{O}_{3}$ hard particles. We used soft particles (graphite) as the second type of reinforcement because that gives to the composite good lubrication properties under dry friction conditions and low expansion coefficient [23].

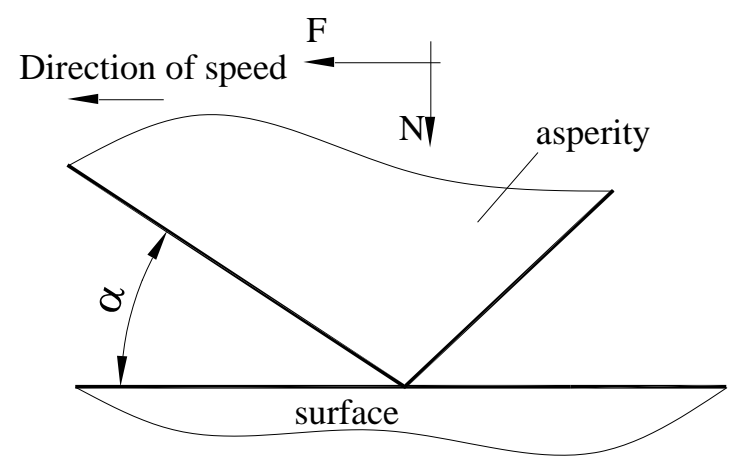

Figure 1 Scheme of asperity displacement

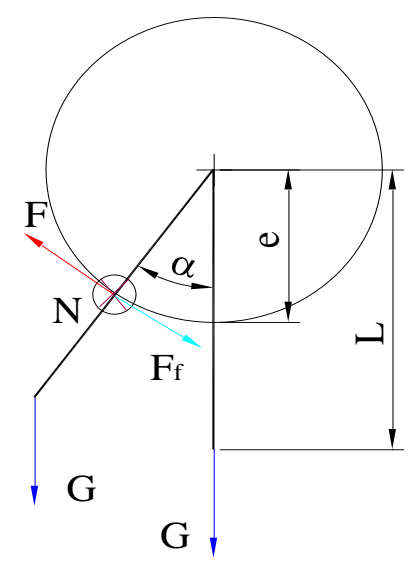

Figure 2: Schematic presentation of the "pin on disc" device with the friction forces involved

\section{- Device description}

Test machine consists of a balanced pendulum, in which mounted the sample into a box (Fig. 2). The sample rub on a cast iron disc (hardness 300HB) and the disc is acted through the main body of a transmission belt by an electric motor of $1.4 \mathrm{~kW}$ power. Peripheral speed of the disc at the sample level is variable through the possibility to fixed the sample box at different distances to the driving axle and helped by the variable transmission. The frictional force was determined by measuring the angular movement $(\alpha)$ of pendulum from the vertical position. The friction coefficient is determined from Coulomb's law:

$$
\mu=\frac{F_{f}}{N}=\frac{L}{e} \cdot \frac{G}{N} \cdot \sin \alpha
$$




\section{- Tribological experiments}

We determined the average friction coefficients for all types of composites and unreinforced matrix in heat treated state (solution treatment at $480 \pm 5^{\circ} \mathrm{C} / 60 \mathrm{~min}$, quenched in water and then, artificial aging at $140 \pm 5^{\circ} \mathrm{C} / 12$ hours, air quenched). The tribological tests were performed on the pin-ondisc type wear machine (Fig. 2) at Mettalurgical Research Institut, in Bucharest, under following condition: contact pressure (applied load) 3.5 and $7.5 \times 10^{-1} \mathrm{MPa}$, relative sliding speed of $3.8 \mathrm{~m} / \mathrm{s}$ at constant temperature. All tests were run under dry sliding conditions. The dimensions of all samples was $10 \times 10 \times 7 \mathrm{~mm}$.

The disc was polished before each tribological test. The time of wear test was kept constant in all cases at $30 \mathrm{~min}$. The frictional force was determined by measuring the angular movement $(\alpha)$ of pendulum from the vertical position. Normal force $\mathrm{N}$ is applied through a smple pushing at the desire value (Fig.2).

\section{Experimental Results}

- Comparison of estimated coefficient of friction, based on the theoretical model, with the results obtained experimentally

Based on equations (4) and (5) of the wave model, the coefficient of friction was calculated by different factors, such as: (a) the adhesion coefficient, (b) the deformation of the materials during the friction process, and (c) the inclination angle of the microasperity resulting from the friction process for metal-metal or metal-ceramic coupling in general and aluminum based composite / cast iron couple in particular.

In Table 1 shows the estimated values of the calculated friction coefficient according to different values of the angle of asperity, and to different coefficients of adhesion $f$ after Eq. (4) and (5) for all studied materials.

Table 1-Adhesion coefficient ( $f$ ) for all studied materials.

\begin{tabular}{|c|c|c|c|}
\hline$f$ & Material type & $f$ & Material type \\
\hline 0 & $\mathrm{Al}-\mathrm{Zn}+3 \% \mathrm{Gr}+0 \% \mathrm{Al} 2 \mathrm{O} 3$ (at $3.5 \mathrm{MPa}$ ) & 0.5 & $\mathrm{Al}-\mathrm{Zn}+1 \% \mathrm{Gr}+5 \% \mathrm{Al} 203($ at $7.5 \mathrm{MPa})$ \\
\hline 0.05 & $\mathrm{Al}-\mathrm{Zn}+2 \% \mathrm{Gr}+0 \% \mathrm{Al} 203$ (at $3.5 \mathrm{MPa}$ ) & 0.6 & $\mathrm{Al}-\mathrm{Zn}+0 \% \mathrm{Al} 203$ (at 3,5 MPa) \\
\hline 0.1 & $\mathrm{Al}-\mathrm{Zn}+1 \% \mathrm{Gr}+0 \% \mathrm{Al} 203$ (at $3.5 \mathrm{MPa}$ ) & 0.65 & $\mathrm{Al}-\mathrm{Zn}+2 \% \mathrm{Al} 203$ (at $3.5 \mathrm{MPa}$ ) \\
\hline 0.15 & $\mathrm{Al}-\mathrm{Zn}+1 \% \mathrm{Gr}+2 \% \mathrm{Al} 203$ (at $3.5 \mathrm{MPa}$ ) & 0.7 & $\mathrm{Al}-\mathrm{Zn}+2 \% \mathrm{Al} 2 \mathrm{O} 3$ (at $7.5 \mathrm{MPa}$ ) \\
\hline 0.2 & $\mathrm{Al}-\mathrm{Zn}+1 \% \mathrm{Gr}+2 \% \mathrm{Al} 203$ (at $7.5 \mathrm{MPa}$ ) & 0.75 & $\mathrm{Al}-\mathrm{Zn}+3 \% \mathrm{Al} 203$ (at 3,5 MPa) \\
\hline 0.25 & $\mathrm{Al}-\mathrm{Zn}+1 \% \mathrm{Gr}+3 \% \mathrm{Al} 203$ (at $3.5 \mathrm{MPa}$ ) & 0.8 & $\mathrm{Al}-\mathrm{Zn}+3 \% \mathrm{Al} 2 \mathrm{O} 3$ (at $7.5 \mathrm{MPa}$ ) \\
\hline 0.3 & $\mathrm{Al}-\mathrm{Zn}+1 \% \mathrm{Gr}+3 \% \mathrm{Al} 203$ (at $7.5 \mathrm{MPa}$ ) & 0.85 & $\mathrm{Al}-\mathrm{Zn}+4 \% \mathrm{Al} 203$ (at $3.5 \mathrm{MPa}$ ) \\
\hline 0.35 & $\mathrm{Al}-\mathrm{Zn}+1 \% \mathrm{Gr}+4 \%$ Al203 (at $3.5 \mathrm{MPa}$ ) & 0.9 & $\mathrm{Al}-\mathrm{Zn}+4 \% \mathrm{Al} 203$ (at $7.5 \mathrm{MPa}$ ) \\
\hline 0.4 & $\mathrm{Al}-\mathrm{Zn}+1 \% \mathrm{Gr}+4 \% \mathrm{Al} 203$ (at $7.5 \mathrm{MPa}$ ) & 0.95 & $\mathrm{Al}-\mathrm{Zn}+5 \% \mathrm{Al} 203$ (at $3.5 \mathrm{MPa}$ ) \\
\hline 0.45 & $\mathrm{Al}-\mathrm{Zn}+1 \% \mathrm{Gr}+5 \% \mathrm{Al} 203$ (at $3.5 \mathrm{MPa}$ ) & 1 & $\mathrm{Al}-\mathrm{Zn}+5 \% \mathrm{Al} 203$ (at $7.5 \mathrm{MPa}$ ) \\
\hline
\end{tabular}

Friction coefficient values greater than one occur when the deformed and shifted material breaks after a certain number of stress cycles (according to the Manson-Coffin criterion). For friction coefficient values lower than those of the molecular adhesion coefficient $(f)$, the material is considered to deform elastically.

The behavior (the mode of response) of the softer material (materials subject to analysis) depends largely on surface processing. Figure 3 shows the maximum values of the inclination angle of the asperity for which produces elastic deformations [11]. It is noted that the deformations are elastic at a maximum inclination angle of $16^{\circ}$ from which the coefficient of adhesion is $f=0,5$. When the angle of inclination of the asperity exceeds a critical value $\left(\alpha_{c r}\right)$, the microchipping $[11,15,16]$ occurs. Figure 4 shows the evolution of the critical slope of the asperity, depending on the coefficient of molecular adhesion $(f)$ for the materials specificated in Table 1 and also, $(\mathrm{Ce})$ is the coefficients of strain hardening (strengthening by cold plastic deformation). The experimentally determined $(\mathrm{Ce})$ values for the studied materials are $C e=0.8 \ldots 1.2$.It is noted that the angle of inclination which occurs microchip depends on the strain hardening properties of the material subject to cold-working ( $\mathrm{Ce}$ ).

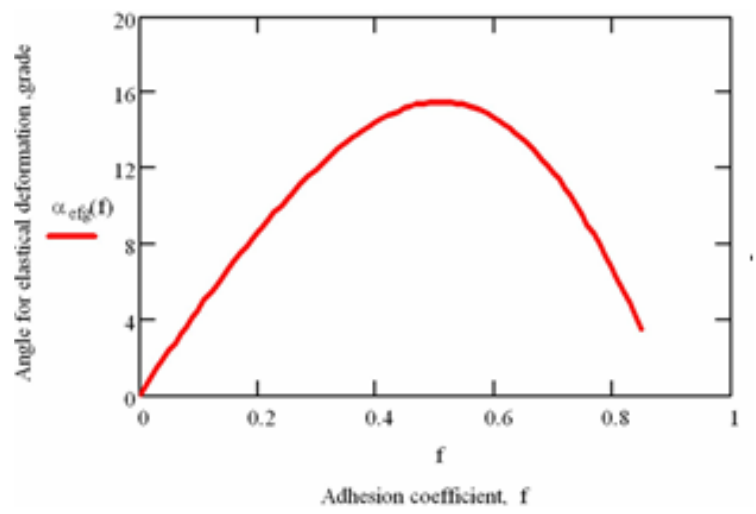

Figure 3: The values of the inclination angle of the asperity for which elastic deformations occur 


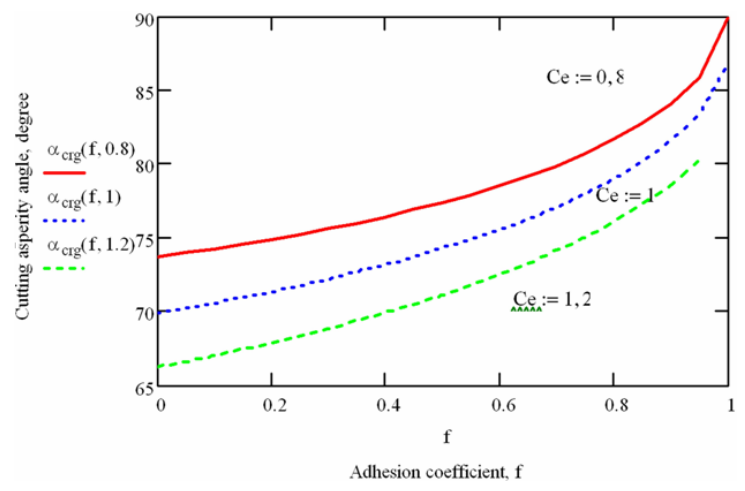

Figure 4. The evolution of the critical slope of the asperity, depending on the coefficient of molecular adhesion $(f)$

The strengthening mechanisms is in relation with dislocation motion and mechanical behavior of metals or metallic matrix composite.

The macroscopic plastic deformation in general increase with reduction mobility of large numbers of dislocations, by age hardening (precipitation hardening) of aluminium matrix (in this case, AlZn6MgCu). When we add hard ceramic particles, the hardness and strength of materials increase, as we explain the mechanism of stregthening at section (Selection of materials). But when we add the soft ceramic particles (alone or in combination with other ceramic particles) in metal matrix composites, the strength and hardness decrease [23, 24].

It is noted that the values of the friction coefficient at the microcrackers increase with the increase of the inclination angle of the asperity and decrease with the increase of the coefficient of molecular adhesion ( $f$ ). This theoretical evolution corresponds to many experimental results obtained in the literature $[13,14,25,26,27]$.

Tables 2, 3 and 4 show both the experimental and the calculated values according to the theoretical model, and in Fig.s 5, 6 and7 show the graphical representations of these values.

Table 2 The experimental and the calculated values of $\mathrm{Al}-\mathrm{Zn}+(1-3) \% \mathrm{Gr}+0 \% \mathrm{Al}_{2} \mathrm{O}_{3}$, according to the theoretical

\begin{tabular}{|c|c|c|c|}
\hline Material type & $\begin{array}{c}\text { Adhesion } \\
\text { coefficient }\end{array}$ & $\begin{array}{c}\text { Experimental Friction coefficient } \\
\text { at applied Load 3.5 MPa }\end{array}$ & $\begin{array}{c}\text { Calculated } \\
\text { Friction coefficient }\end{array}$ \\
\hline $\mathrm{Al}-\mathrm{Zn}+3 \% \mathrm{Gr}+0 \% \mathrm{Al}_{2} \mathrm{O}_{3}$ & $\mathrm{f}=0$ & 0.377 & $0.684 \ldots 0.932$ \\
\hline $\mathrm{Al}-\mathrm{Zn}+2 \% \mathrm{Gr}+0 \% \mathrm{Al}_{2} \mathrm{O}_{3}$ & $\mathrm{f}=0,05$ & 0.326 & $0.651 \ldots 0.888$ \\
\hline $\mathrm{Al}-\mathrm{Zn}+1 \% \mathrm{Gr}+0 \% \mathrm{Al}_{2} \mathrm{O}_{3}$ & $\mathrm{f}=0,1$ & 0.305 & $0.62 \ldots 0.847$ \\
\hline
\end{tabular}

Table 3 The experimental and the calculated values of $\mathrm{Al}-\mathrm{Zn}+1 \% \mathrm{Gr}+(2-5) \% \mathrm{Al}_{2} \mathrm{O}_{3}$, according to the theoretical

\begin{tabular}{|c|c|c|c|c|}
\hline \multirow{2}{*}{ Material type } & \multirow{2}{*}{$\begin{array}{c}\text { Adhesion } \\
\text { coefficient }\end{array}$} & $\begin{array}{c}\text { Experimental Friction coefficient } \\
\text { at Applied Load } \\
3.5 \mathrm{MPa}\end{array}$ & $\begin{array}{c}\text { at Applied Load } \\
7.5 \mathrm{MPa}\end{array}$ & $\begin{array}{c}\text { Friction } \\
\text { coefficient }\end{array}$ \\
\hline $\mathrm{Al}-\mathrm{Zn}+1 \% \mathrm{Gr}+2 \% \mathrm{Al} 203$ & $\begin{array}{c}\mathrm{f}=0.15 \\
\mathrm{f}=0.20\end{array}$ & 0.458 & 0.464 & $\begin{array}{c}0.589 \ldots 0.808 \\
0.56 \ldots 0.777\end{array}$ \\
\hline $\mathrm{Al}-\mathrm{Zn}+1 \% \mathrm{Gr}+3 \% \mathrm{Al} 203$ & $\begin{array}{l}\mathrm{f}=0.25 \\
\mathrm{f}=0.30\end{array}$ & 0.47 & 0.477 & $\begin{array}{l}0.532 \ldots 0.734 \\
0.505 \ldots 0.699\end{array}$ \\
\hline $\mathrm{Al}-\mathrm{Zn}+1 \% \mathrm{Gr}+4 \% \mathrm{Al} 203$ & $\begin{array}{c}\mathrm{f}=0.35 \\
\mathrm{f}=0.40\end{array}$ & 0.471 & 0.472 & $\begin{array}{l}0.478 \ldots 0.666 \\
0.452 \ldots 0.634\end{array}$ \\
\hline $\mathrm{Al}-\mathrm{Zn}+1 \% \mathrm{Gr}+5 \% \mathrm{Al} 203$ & $\begin{array}{l}\mathrm{f}=0.45 \\
\mathrm{f}=0.50\end{array}$ & 0.501 & 0.518 & $\begin{array}{l}0.426 \ldots 0.602 \\
0.401 \ldots 0.571\end{array}$ \\
\hline
\end{tabular}

Table 4 The experimental and the calculated values of $\mathrm{Al}-\mathrm{Zn}+(0-5) \% \mathrm{Al}_{2} \mathrm{O}_{3}$, according to the theoretical model

\begin{tabular}{|c|c|c|c|c|}
\hline Material type & $\begin{array}{c}\text { Adfesion } \\
\text { coefficient }\end{array}$ & $\begin{array}{c}\text { Applied Load } \\
3.5 \mathrm{MPa}\end{array}$ & $\begin{array}{c}\text { Applied Load } \\
7.5 \mathrm{MPa}\end{array}$ & $\begin{array}{c}\text { Calculated } \\
\text { Friction coefficient }\end{array}$ \\
\hline $\mathrm{Al}-\mathrm{Zn}+0 \% \mathrm{Al} 203$ & $\mathrm{f}=0.6$ & 0.424 & 0.44 & $0.353 \ldots 0.512$ \\
\hline $\mathrm{Al}-\mathrm{Zn}+2 \% \mathrm{Al} 203$ & $\begin{array}{c}\mathrm{f}=0.65 \\
\mathrm{f}=0.70\end{array}$ & 0.483 & 0.51 & $\begin{array}{l}0.329 \ldots 0.483 \\
0.305 \ldots 0.455\end{array}$ \\
\hline $\mathrm{Al}-\mathrm{Zn}+3 \% \mathrm{Al} 203$ & $\begin{array}{c}\mathrm{f}=0.75 \\
\mathrm{f}=0.80\end{array}$ & 0.509 & 0.525 & $\begin{array}{l}0.281 \ldots 0.426 \\
0.258 \ldots 0.398\end{array}$ \\
\hline $\mathrm{Al}-\mathrm{Zn}+4 \% \mathrm{Al} 203$ & $\mathrm{f}=0.85$ & 0.516 & 0.531 & $\begin{array}{l}0.234 \ldots 0.37 \\
0.21 \ldots 0.342\end{array}$ \\
\hline $\mathrm{fl}=0.90$ & $\mathrm{f}=0.95$ & 0.537 & 0.573 & $\begin{array}{l}0.186 \ldots 0.314 \\
0.162 \ldots 0.285\end{array}$ \\
\hline
\end{tabular}




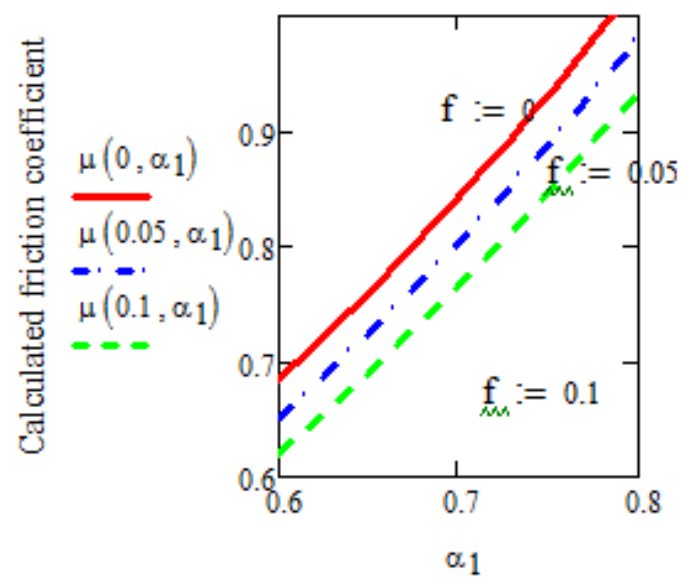

Angle deformation

(a)

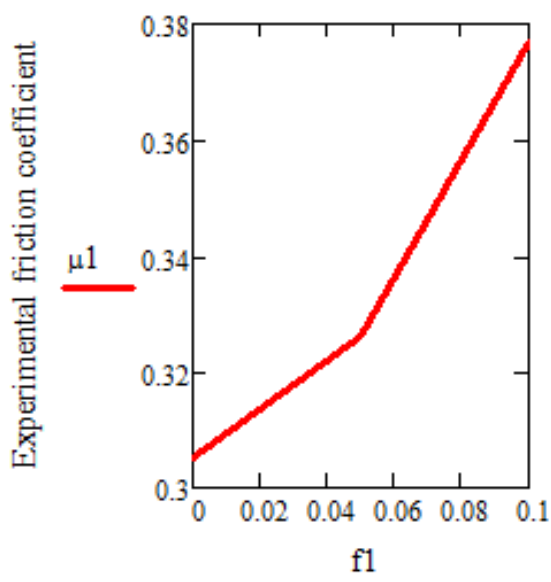

Adhesion coefficient

(b)

Figure 5. Evolution of the theoretical and experimental friction coefficient for $\mathrm{Al}-\mathrm{Zn}+1 \%$ to $3 \% \mathrm{Gr}+0 \%$

Al203, (a) Theoretical evolution of the friction coefficient depending on the inclination angle of the roughness; (b) The evolution of the experimental friction coefficient according to the coefficient of adhesion

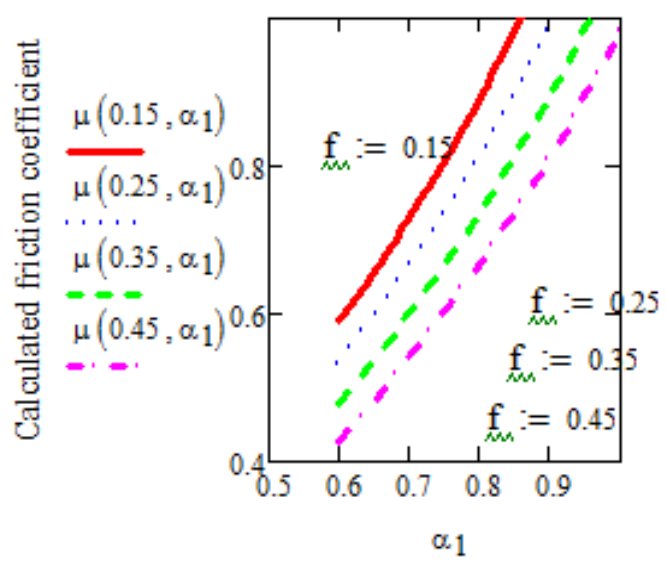

Angle deformation

(a)

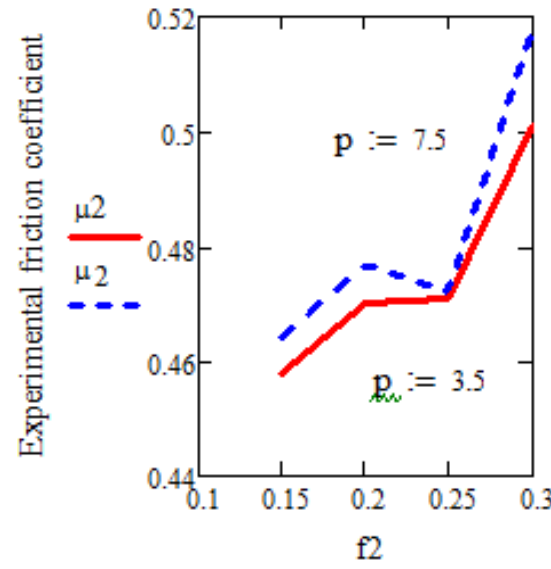

Adhesion coefficient

(b)

Figure 6. Evolution of the theoretical and experimental friction coefficient for $\mathrm{Al}-\mathrm{Zn}+1 \% \mathrm{Gr}+(2-5) \% \mathrm{Al}_{2} \mathrm{O}_{3}$,

(a) Theoretical evolution of the friction coefficient depending on the inclination angle of the roughness; (b) The evolution of the experimental friction coefficient according to the coefficient of adhesion

\section{Conclusions}

Research on the friction coefficient has shown that Coulomb's law, according to which the friction coefficient depends on the normal applied force, is valid only for certain operating conditions of the friction coupler.

In fact, research conducted over time has shown that the coefficient of friction is not independent of speed and pressure as Coulomb thought $[28,29,30]$.
The laws established by Coulomb have proved to be valid only in the case of dry rubbing and in the conditions of elastic deformations of the asperities of the surfaces in contact, in a sliding movement (dry sliding conditions).

There are no fundamentally different values between experimental and theoretical slip coefficient values. The obtained experimental values greater then the theoretical ones are explained as follows: (i) increasing the real contact area due to the friction force; (ii) the occurrence of additional forces when the material deforms in the form of a wave. 


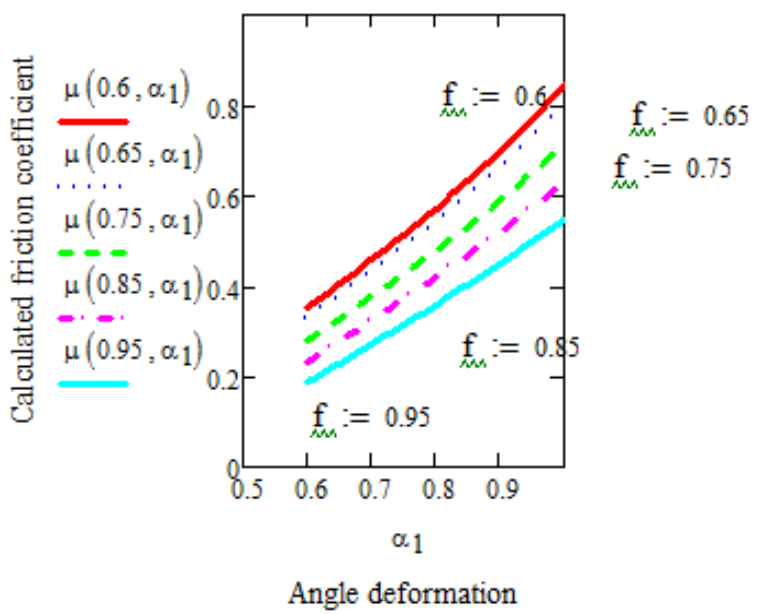

(a)

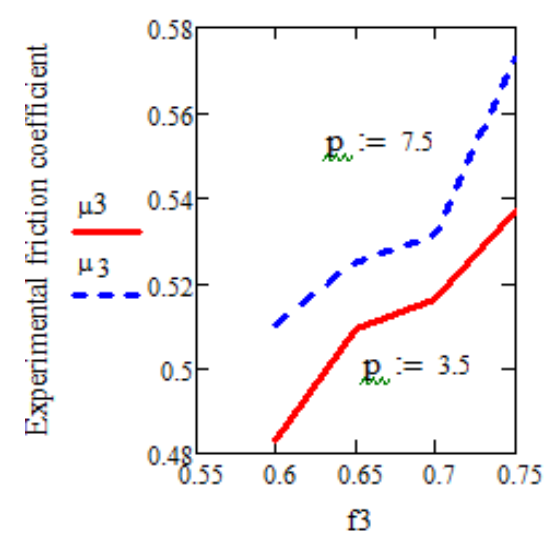

Adhesion coefficient

(b)

Fig. 7. Evolution of the theoretical and experimental friction coefficient for $\mathrm{Al}-\mathrm{Zn}++(\mathrm{O}-5) \% \mathrm{Al}_{2} \mathrm{O}_{3},(\mathrm{a})$ Theoretical evolution of the friction coefficient depending on the inclination angle of the roughness; (b) The evolution of the experimental friction coefficient according to the coefficient of adhesion

The experimental values obtained lower than the theoretical values are due to the different adherence of the materials in the formation of micro-junctions. In the theoretical model, we taken into account: (a) the mode of processing surface and also (b) the characteristics of the material, but we have not been taken into account the coupling load.

The proportion of friction coefficient components (adhesion, deformation or/and breaking) depends on the angle inclination, the shape of the asperities and the properties of the materials: (a) - the adhesion component depends on the state of lubrication and the nature of the surface; (b) - the deformation component depends on the lubrication state and the inclination of the asperities(the asperity angle); (c) - the abrasion component occurs when the angle of the asperity exceeds a critical value and the materials have essentially different hardnesses. In the case of anti-friction materials, in order to have high performance tribological characteristics, we must have graphite and hard ceramic particle for hardening the metal matrix.

\section{References}

[1] R.K. Uyyuru, M.K. Surappa, S. Brusethaug, Tribological behavior of Al-SiSiCpcomposites/automobile brake pad system under dry sliding conditions, Tribology International 40, 2007, 365-373

[2] I.N. Popescu, C. Ghiţă, V. Bratu, G. Palacios Navarro, Tribological behaviour and statistical experimental design of sintered iron-copper based composites, Applied Surface Science 285 (PartA), 2013, 72-85

[3] N. Popescu, V. Bratu, F. V. Anghelina and L. G. Toma, The Effect of Wear Test Parameters on
Tribological Characteristics of Aluminium Based Composites, The Scientific Bulletin of Valahia University - Materials and Mechanics, Nr. 6 (year 9), 2011, 83-86

[4] Buckley, D.H., Surface Effects in Adhesion, Friction, Wear, and Lubrication, Elsevier, Amsterdam, Tribology serie 5, 1981, ISBN 0444-41966-7

[5] P.J. Blau, Friction Science and Technology, Marcel Dekker, New York, 1996, ISBN 0824795768

[6] L.J. Yang A test methodology for the determination of wear coefficient, Wear 259, 2005, 1453-1461

[7] L.J. Yang, Wear coefficient eguation for aluminium/based matrix composites against steel disc, Wear 255, 2003, 579-592

[8] S. Wilson, A.T. Alpas, Wear mechanism maps for metal matrix composites, Wear 212(1), 1997, 41-49

[9] Tudor, M. Vlase, Uzarea materialelor, Ed Bren, ISBN 978-973-648-938-9, Bucureşti 2010, 232246

[10] Tudor, Frecarea şi uzarea materialelor, Ed Bren, ISBN 973-648-070-4, Bucureşti 2002, 158-178

[11] Petre, Wear model of sliding surfaces used in the machine-tools industry, The Scientific Bulletin of Valahia University, Materials and Mechanics, nr.9 (year 12) 2014, 99-104

[12] M. Sikorski, Correlation of the Coefficient of Adhesion with Various Physical and Mechanical Properties of Metals, Trans. ASME D. 85, 1963, 279-284

[13] F.P. Bowden, and D. Tabor, The Area of Contact Between Stationary and Between Moving Surfaces, Proc. R. Soc. London, Ser. A, 169, 1939, $391-413$ 
[14]J.M. Challen, L.J. McLean, and P.L.B. Oxley, Plastic Deformation of a Metal Surface in Sliding Contact With a Hard Wedge: Its Relation to Friction and Wear, Proc. R. Soc. London, Ser. A, 394, 1984, 161-181

[15]J. Challen, and P.L.B. Oxley, An Explanation of the Different Regimes of Friction and Wear Using Asperity Deformation Models, Wear 53, 1973, 229-243

[16]R. Lovell Michael, P. Cohen, Pradeep L. Menezes, R. Shankar, Tribological Characterization of Machining at Very Small Contact Areas, Journal of Tribology, Vol. 131, Transactions of the ASME, 2009

[17]E.M. Kopalinsky, and P.L.B Oxley, Explaining the mechanics of metallic sliding friction and wear in terms of slipline field models of asperitz deformation, Wear 290, 1995, 145-154

[18]F.P. Bowden, D. Tabor, The friction and lubrication of solid Clarendon Press Oxford Universitz Press, Oxford Pt. I, 1954, Pt.II 1964

[19]M.R. Lovell, and Z. Deng, Experimental Investigation of Sliding Friction Between Hard and Deformable Surfaces With Application to Manufacturing Processes, Wear, 2361-2, 1999, 117-127

[20]M.C. Enescu, I. N. Popescu, R. Zamfir, A Molagic, V Bratu, Experimental researches on the corrosion behavior and microstructural aspects of heat treated Al-Zn-Mg-Cu alloys, International Journal of Energy and Environment, 4(4) 2010, 122-130

[21]N. Popescu, R. Vidu, V. Bratu, A. B. Olei, D. N. Ungureanu, F. V. Anghelina, Effects of Silicon Carbide Proportion and Artificial Aging Parameters on Microstructure and Hardness of Al-Cu/SiCp Composites, Solid State Phenomena, Vol. 216, 2014, 122-127

[22]I.N. Popescu, V. Bratu, M.C. Enescu, Experimental researches and statistical analysis of the corrosion behavior of rolled and heat treated 2xxx Al alloys, AEE '10: Proceedings of the 9th WSEAS International Conference on applications of electrical engineering, 2010, $225-232$.
[23]M.O. Bodunrin, K.K. Alaneme, L.H. Chown, Aluminium matrix hybrid composites: a review of reinforcement philosophies; mechanical, corrosion and tribological characteristics, J. MATER. RES. TECHNOL., 4(4), 2015, 434-445

[24]I.N. Popescu, V. Bratu, M. Ionescu, M. Chivu, M.C. Enescu, A.A. Poinescu, Preparation and characterization of cast Aluminium/Graphite Composites and Hybrid Aluminium Composites, The Scientifi Bulletin of Valahia UniversityMaterials and Mechanics, nr.4 (year 7), 2009, 104-108

[25]A.J. Black, E.M. Kopalinsky, and P.L.B. Oxley, An Investigation of the Different Regimes of Deformation Which Can Occur When a Hard Wedge Slides Over a Soft Surface: The Influence of Wedge Angle, Lubrication and Prior Plastic Working of the Surface, Wear, 123(1), 1988, 97-114

[26]J.M. Challen, and P.L.B. Oxley, A Slip Line Field Analysis of the Transition From Local Asperity Contact to Full Contact in Metallic Sliding Friction, Wear 100, 1984, 171-193

[27]Y. Yang, A.A. Torrance, and P.L.B. Oxley, Modelling Mechanical Wear Processes in Metallic Sliding Friction, J. Phys. D, 29, 1996, 600-608

[28]L. Francis Xavier and Suresh Paramasivam, Wear Behavior of Aluminium Metal Matrix Composite Prepared from Industrial Waste, ScientificWorl Journal, 2016: 6538345, Published online doi: 10.1155/2016/6538345

[29]G. B. Veeresh Kumar, C.S.P. Rao, N. Selvaraj, Mechanical and Tribological Behavior of Particulate Reinforced Aluminum Metal Matrix Composites, Journal of Minerals \& Materials Characterization \& Engineering, Vol. 10, No.1, 2011, 59-91, jmmce.org doi: 10.4236/jmmce.2011.101005

[30]M. Selvaraj, M.S.Alphin, M. Nalla Mohamed, G.Selvakumar, Investigation of Mechanical and Tribological Behaviour of Dual Particles Reinforced Al Matrix Composites, Applied Mechanics and Materials (Volume 852), 2016, 422-427, doi10.4028/www.scientific.net/AMM.852.422. 